\title{
Duas Matemáticas: percurso e co-construção das formas dedutiva e procedimental
}

Two Maths: historical path and co-construction of deductive and procedural forms

Isabel Cafezeiro ${ }^{1}$

Ricardo Kubrusly ${ }^{2}$

\section{Resumo}

A partir da história de construção da forma dedutiva da matemática, argumentamos que esta sempre foi acompanhada por uma outra forma de apresentação matemática que privilegiou o "fazer", assumindo a aparência de descrição, procedimentos ou receitas. Percebemos a impossibilidade de uma forma "pura" (puramente dedutiva ou puramente procedimental), e portanto, uma mútua dependência entre as duas formas de apresentação. Porém, na presença de uma configuração de poder que privilegiou o intelecto, a matemática dedutiva se sobrepôs à matemática procedural, situando esta última como um saber desprestigiado. Sob a perspectiva da História das Ciências, este texto indica ao professor de matemática a importância de conciliar as duas formas de apresentação. No século XX, a computação novamente traz luz à matemática procedimental, exigindo novos arranjos nas formas de apresentação das matemáticas.

Palavras chave: matemática dedutiva; matemática procedimental; história da ciência.

\begin{abstract}
From the historical construction of the deductive form of mathematics, we argue that this has always been accompanied by another kind of mathematical presentation that has privileged "doing", assuming the appearance of description, procedures or recipes. We perceive the impossibility of a "pure" form (purely deductive or purely procedural), and therefore, a mutual dependence between the two forms of presentation. However, in the presence of a power configuration that favored the intellect, deductive mathematics overlapped procedural mathematics, placing the latter as discredited knowledge. From the perspective of the History of Sciences, this text indicates to the mathematics teacher the importance of reconciling the two forms of presentation. In the 20th century, computing again sheds light on procedural mathematics, requiring new arrangements in the presentation of mathematics.
\end{abstract}

Keywords: deductive mathematics; procedural mathematics; history of science.

\footnotetext{
${ }^{1}$ Universidade Federal Fluminense | isabel@ic.uff.br

${ }^{2}$ Universidade Federal do Rio de Janeiro | risk@hcte.ufrj.br
} 


\section{Das cavernas, marcas para a eternidade}

Eu não tenho dúvida nenhuma de que a nossa presença no mundo, implicou indiscutivelmente a invenção do mundo. (FREIRE,1996)

Ao sair da caverna, o humano primitivo se vê diante do desconhecido e do inesperado: um bisão. Amedrontado, retorna à caverna e desenha o bisão. Desenha também a si próprio, estampa suas próprias mãos nas paredes, e desenha a si enfrentando o bisão. Assim, através do desenho, ele se (re)conhece. Elabora seus medos e cria suas maneiras de transformar o mundo em que vive. A questão primordial dos humanos é, e sempre foi, driblar a morte, por isso, deixa marcas que deverão ultrapassar a sua própria vida. Tendo consciência da própria morte, o homem busca meios de alongar sua vida indefinidamente. "A morte é o começo de tudo", canta o poeta Antônio Nóbrega. É a busca pelo infinito.

Aí se origina toda a matemática que conhecemos hoje: no momento em que o humano, pela representação, busca compreender o seu tempo e espaço, e assim constrói o seu lugar como sujeito de si e do seu mundo. "A matemática como uma condição de estar no mundo", disse Paulo Freire (1996) em tempos recentes.

A matemática surge indistinta da linguagem, da arte, indistinta da vida, é a expressão de homens e mulheres diante das suas demandas, dos seus conflitos, na busca da construção de sua identidade. Assim, como expressão das coisas da vida, a matemática prossegue ao longo da história humana. A proximidade entre a representação e o problema vivido motiva uma forma procedimental, uma descrição de "como fazer". Os desenhos nas paredes, ou seja, a matemática daqueles tempos, mostram os modos de caçar, de conviver, que eram a ciência daquele momento.

Outras matemáticas surgiram em outros tempos a partir de outras demandas, sempre em resposta às necessidades imediatas da vida de então. O ser humano, fixado na terra pela agricultura que se iniciou por volta de 10.000 a.C, passou a sentir necessidade de trabalho em grupo, divisão da produção, trocas. Surgem feiras, vilas, primeiras cidades, em torno dos rios Tigre e Eufrates, localizados no atual Oriente Médio. Acompanhando esta outra maneira de estar no mundo seguem-se outras maneiras de expressar a própria existência. O comércio incipiente demanda registros das trocas, daí inventam-se os símbolos cunhados em placas de argila, a escrita cuneiforme dos Sumérios (3500 a.C). Estas placas sobreviveram à destruição da Suméria por guerras e chegaram aos babilônios (1830 a.C a 539 a.C), tornando acessível um conhecimento que possivelmente já havia alcançado o que hoje chamamos frações, álgebra, equações quadráticas e cúbicas e o que posteriormente recebeu o nome de "Teorema de Pitágoras". Em tempos próximos, os Egípcios inventaram símbolos sagrados, seus hieróglifos, para escrever mensagens em templos e túmulos, novamente a matemática indistinta da arte e da vida, expressão de estar no mundo.

Os povos Sumérios, e posteriormente, Egípcios e Babilônios (entre os séculos XVIII e VI a.C), se aprimoraram nas descrições de seus processos por causa das necessidades recorrentes de medir áreas. Bem mais tarde, por volta do ano 440 a.C, Heródoto, um grande estudioso do mundo e do modo de viver de povos anteriores ao seu tempo, teve a preocupação de registrar os costumes dos povos antigos na região em torno do Mar Mediterrâneo e norte da África. Ele deixou claras as demandas decorrentes das variações climáticas e cheias dos rios em tempos que precederam seu nascimento. Mostrou, em seus relatos, que em terras entre-rios, nem o chão em que se pisa é consolidado:

Se o rio carregava alguma parte do lote de alguém, o prejudicado ia procurar o rei e expor-lhe 0 acontecido. $O$ soberano enviava 
agrimensores ao local para determinar a redução sofrida pelo lote, passando o dono a pagar um tributo proporcional à posição restante. Eis, segundo me parece, a origem da geometria, que teria passado desse país para a Grécia. (HERÓDOTO, Livro II, parágrafo CIX)

Assumindo forma diversa a cada cheia, o terreno variante parece ter demandado muita matemática. Possivelmente daí desenvolveu-se a leitura dos astros para compreender os movimentos dos rios, o cálculo de áreas para refazer a divisão das terras e recalcular as tarifas em terras arrendadas ao povo pelo Faraó. Assim vemos que aqui, como nas cavernas, a aderência ao problema em questão faz surgir um estilo procedimental, enfatizando "como fazer", geometria: como medir a terra. O historiador da matemática J. Ritter (1989) comparou um texto egípcio e outro babilônico, ambos do entorno do terceiro milênio. Os dois textos endereçavam um mesmo problema, calcular a capacidade de armazenamento de um silo. Destacou-se o estilo procedimental:

Caracteriza-se por uma apresentação retórica; no sentido de que os problemas se expressam em palavras (da linguagem cotidiana) e não em símbolos; numérica: dados e resultados são números concretos e não abstrações; algorítmica: com uma série específica de etapas de resolução e sem demonstrações gerais. (RITTER, 1989, p.44)

Nessa apresentação retórica, numérica e algorítmica, Ritter, chama atenção para a inexistência do simbolismo matemático (equações, fórmulas) que caracterizam os escritos modernos, bem como a participação direta do autor (escriba) cuja "voz" aparece explicitamente na solução. $O$ texto algorítmico era uma narrativa na segunda pessoa, que podia estar em tempo futuro ou no imperativo: "para fazer um silo redondo de 9 (e de) 10 tu subtrairás 1/9 de 9: 1..." (RITTER, 1989, p.43)

O estudo comparativo das apresentações matemáticas da antiguidade nos mostra desenvolvimentos diferentes entre si, completamente inseridos nas condições locais de vida em sociedade e cultura. Isto faz cair por terra a ideia de que haveria uma "natureza" própria, interna, autônoma, que caracterizaria "a matemática" e nos leva a compreender que "matemática se escreve no plural". Além disso, também desconstrói o pré-conceito de que a ciência evolui linear e cumulativamente, ao mostrar que os movimentos fundadores da ciência não se assemelham ao ao que ela é agora (RITTER, 1989, p.60).

\section{A formação de um saber privilegiado}

Nos dias de hoje, após muitos séculos de um percurso matemático que se envergonha da aproximação com a vida e reivindica para si o prestígio de um saber que se estabelece somente a nível do raciocínio apurado, presenciamos o testemunho inconformado daqueles que buscam para a "Rainha das Ciências" uma origem fidalga. Estes, analisando o percurso das matemáticas antigas, ainda esperam encontrar sinais de uma racionalidade não desvelada:

Os ensinamentos eram transmitidos na forma: "faça isso, depois isso, em seguida isso e esse é o resultado". É difícil acreditar que certas "receitas" apresentadas pelos matemáticos babilônicos tenham sido descobertas apenas por tentativas, sendo provável que algum raciocínio lógico, não explicitado, tenha sido usado (GARBI, 2007, p.12). 
Outros textos famosos da atualidade, adotam uma concepção evolutiva cujo parâmetro é a matemática praticada nos dias de hoje, ficando subjugado o atendimento às demandas de um povo em seu tempo e ambiente. Nessa perspectiva, consideram como "deficiências da matemática" daquele tempo e lugar a falta de um raciocínio lógico explícito e desvinculado das práticas. Uma matemática evoluída seria uma expressão abstrata, isto é, a expressão descolada das coisas do mundo que the serviram de inspiração:

Os papiros e tabletas encontrados contém apenas casos específicos e problemas, sem formulações gerais, e pode-se perguntar se essas civilizações antigas realmente percebiam os princípios unificadores que estão no centro da matemática (BOYER,1999, p.28).

São muitas as evidências de que o conhecimento matemático não tem suas origens no mais nobre intelecto por meio do raciocínio lógico, ao contrário, essas histórias antigas mostram que estava, desde sempre, na feira, no comércio, na agricultura, na fé, para resolver questões imediatas da vida e da busca humana por explicações diante de sua finitude. Esses ambientes turbulentos permitiram uma confluência de fatores que estimularam o pensamento de modo a criar as mais diversas expressões e soluções. Sob este ponto de vista, a matemática de 'receitas' é suficientemente evoluída, a ponto de resolver as demandas do seu tempo e local.

Por volta do século $\mathrm{VI}$ a.C, o povo grego passou a tomar conhecimento da matemática egípcia e babilônica. A vida, em especial, a atividade do comércio, foi o que fomentou e possibilitou esse intercâmbio em pelo menos dois episódios: a cessão de Náucratis aos gregos e as viagens do comerciante Tales. Conta Heródoto, que o faraó egípcio Amásis, que governou entre 570 e 526 a.C, permitiu, a instalação de um ponto de comércio na cidade de Náucratis, uma decisão que não somente atendeu à simpatia de Amásis aos Gregos, mas também à iniciativa de concentrar os gregos em Náucratis, amansando um certo incômodo com relação à presença deles no Egito (HERÓDOTO, livro II, parágrafo CLXXVIII). Em alguns trechos, Heródoto se refere às célebres cortesãs como Ródope, contemporânea de Amásis: "As cortesãs de Náucratis são geralmente dotadas de grande beleza" (Heródoto, livro II, parágrafo CXXXV). A menção às cortesãs e seus prestigiados serviços nos leva a pensar que aquele teria sido um centro efervescente. Nesse ambiente de grande circulação, os papiros egípcios devem ter chegado aos Gregos possivelmente em troca das produções gregas como tecido, vinho, cerâmica e azeite. Contrabando, comércio, cortesãs, a vida pulsante, eis um lugar propício para o desenvolvimento da matemática. Outro motivo fomentador do intercâmbio entre gregos e egípcios foi a viagem de Tales de Mileto (623 a.C a 556 a.C) ao Egito. Não parece ter sido uma viagem para fins de comércio, ao contrário, Tales pretendia "gozar da palestra dos sacerdotes e astrônomos do país" (SOUZA, 1956, p.368). Entretanto sabe-se que Tales foi um próspero e inteligente comerciante grego, e isto o colocava em uma posição privilegiada, com acesso às pessoas importantes na sociedade egípcia, ao ponto de visitar a Pirâmide de Quéops na companhia do próprio Amásis.

Não há hoje documento original autenticando os métodos de Tales, mas há quem diga que ele teria sido responsável pelas primeiras apresentações de provas dedutivas na matemática, e por isso alguns o consideram o pai da matemática dedutiva. As informações que hoje dispomos foram em grande parte disseminadas a partir do Livro History of Geometry de Eudemus de Rhodes (370 aC a 300 aC), anterior a Euclides. No entanto, a obra de Eudemos se perdeu e o que se sabe hoje é devido a citações de outros historiadores da 
Grécia antiga, como Proclo (412 a 485). Por exemplo, no Comentário sobre o Livro I de Euclides, Proclo dá diversas pistas sobre Tales, bem como sobre os pitagóricos, sugerindo uma concepção dedutiva da matemática:

Tales, que viajou para o Egito, foi o primeiro a introduzir essa ciência na Grécia. (...) Pitágoras transformou a Filosofia Matemática em um esquema de educação liberal, examinando seus princípios do alto para baixo e investigando seus teoremas de uma maneira imaterial e intelectual. (PROCLO, p.52-53) (...) Eudemo, o Peripático, atribui aos pitagóricos a descoberta deste teorema de que os ângulos internos de cada triângulo são iguais a dois ângulos retos. Ele diz que eles provaram o teorema em questão (...) ". (PROCLO, p.298)

Souza e Boyer discordaram, situando na concepção dos conceitos (e não na construção de demonstrações) a grande contribuição de Tales:

Não se trataria, propriamente, de uma demonstração, mas da apresentação de um desenho geométrico, explicando uma das primeiras observações científicas. No caso, o que era novo, de uma novidade extraordinária, estava na observação teórica, e não no desenho, a bem dizer (SOUZA,1956, p.373).

(...) Tales foi frequentemente saudado como o primeiro matemático verdadeiro - originador da organização dedutiva da geometria. Esse fato, ou lenda, foi ornamentado, acrescentando-se a esse teorema [que um ângulo inscrito em um semi-círculo é um ângulo reto] outros quatro que se dizia provados por Tales. (...) Não há documento antigo que possa ser apontado como prova desse feito, no entanto, a tradição é persistente. (BOYER, 1999, p.32)

Também Pitágoras (570 a.C a 495 a.C) costuma receber as honras de ter iniciado o processo dedutivo na matemática, o que levanta suspeitas em função da compreensão pitagórica de números como coisas concretas, algo espacialmente extenso. Por exemplo, para os pitagóricos "O número ímpar em geral, e o número 3 em particular, era definido (...) como 'aquele que tem um começo, um meio e um fim'. O número par, por outro lado (...), não tem 'meio'" (KIRK \& RAVEN,2010, p.250). Como os pitagóricos tinham uma tradição oral, não restou um documento que nos permita dizer ao certo que tipo de apresentação da matemática eles praticavam. Mas, a aproximação com o concreto parece sugerir que a matemática pitagórica se colocava distante de se apresentar como um encadeamento formal de argumentos.

\section{"Desde os gregos, quem diz matemática diz demonstração"}

Outros grandes matemáticos posteriores a Pitágoras foram Eudoxo de Cnido (408 a.C a 355 a.C) e seu professor, o pitagórico Arquitas de Tarento (428 a.C a 347 a.C). Possivelmente, Eudoxo e Arquitas tenham vivenciado os primeiros passos do que viria a constituir uma prática matemática descolada do mundo. Plutarco, um historiador grego que viveu no século I (46 d.C. a 120 d.C), se referiu aos dois do mesmo modo, chamando atenção ao caráter prático da matemática (evidências da aderência à vida mundana), mas também ao conhecimento abstrato expresso em palavras e diagramas: 
Eudoxos e Arquitas foram os precursores desta muito famosa e altamente valorizada arte da mecânica, que eles empregaram como uma ilustração elegante de verdades geométricas, e como um meio de sustentar experimentalmente, para a satisfação dos sentidos, conclusões muito complicadas de serem provadas por palavras e diagramas (PLUTARCO, 1839, p. 697).

Plutarco deixou claro também que havia, a esta época, uma declarada oposição a uma apresentação procedural e aplicada da matemática. Era um investimento disciplinar para assegurar um território exclusivo do intelecto para a matemática:

Mas com a indignação de Platão e suas injúrias contra isto como mera corrupção e aniquilação da boa geometria - que foi, assim, vergonhosamente virando as costas aos não-corpóreos objetos de pura inteligência para recorrer a sensação, e pedir ajuda (que não seria obtida sem subserviência e depravação) à matéria; foi assim que a mecânica veio a ser separada da geometria e, repudiada e negligenciada por filósofos, tomou o seu lugar como uma arte militar (PLUTARCO, 1839, p. 697).

Alguns trechos d'A República de Platão (428 a.C a 348 a.C) exemplificam a afirmação de Plutarco, a defesa de uma matemática desprendida do mundo:

Sócrates: ela tem por objeto o conhecimento do que existe sempre, e não do que nasce e perece. (...) Portanto, meu dileto amigo, ela atrai a alma para a verdade e desenvolve esse pensamento filosófico que eleva para o alto os olhares que indevidamente baixamos para as coisas deste mundo. (PLATÃO, 1997, p.239)

A concepção de Platão com relação à matemática se explica a partir de seu momento de vida, e daí também a concepção geral que ele constrói a respeito do conhecimento e da vida. Observemos, primeiramente, que o texto de Platão é em forma de diálogo, uma transição entre a tradição oral de transmissão de conhecimento filosófico, como fazia o seu mestre Sócrates (469 a.C a 339 a.C), e a tradição formalizada pela escrita, que se efetivará com os escritos de seu discípulo Aristóteles (384 a.C - 322 a.C). Ao fixar as palavras no texto, Platão inicia uma prática de abstração, definindo a forma do argumento. A apresentação dedutiva é uma radicalização máxima deste processo buscando eliminar por completo a fluidez, instabilidade e evasivas da narrativa oral. Mas a transição não se dá somente na expressão literária. Platão viveu a sociedade ateniense em um período de decadência pósguerras. Ele testemunhou uma época de corrupção, injustiça e descrença no poder estabelecido, a ponto de renderem sátiras nas peças de seu contemporâneo Aristófanes, como Pluto, o Deus da Riqueza (ARISTÓFANES, 1989). Platão enxergou no intelecto uma saída para livrar-se deste cenário e alimentar expectativas de tempos melhores. Essas questões presenciadas por ele se refletiram diretamente na sua obra não somente pela escolha do tema central d'A República, que é a justiça, mas também no desenvolvimento de sua abordagem filosófica. Platão depositava no intelecto o caminho para a verdade. Entendia que a sabedoria e a razão livrariam o governo da corrupção e injustiças. Contrapunha o mundo das ideias ao mundo sensível (das sombras). Este último diria respeito a uma esfera subjetiva, a visão humana e sua interpretação sobre as coisas do mundo, algo efêmero, impreciso e incerto. O mundo das sombras poderia também corresponder a um mundo de equívocos e ilusões, como ele relata na alegoria da caverna (PLATÃO, 1997, Livro VII). Por sua vez o mundo das ideias diria respeito a verdade mais crua. Desvinculado da matéria, as ideias seriam eternas e imutáveis, e alcançáveis através de 
um raciocínio apurado. Daí a rejeição de uma apresentação da matemática vinculada à prática e a insistência por uma apresentação esquemática, abstrata, um afastamento das coisas corriqueiras (menores) da vida.

Hoje, a acompanhando as propostas dos antigos e as conjunturas em que se formaram, percebemos a impossibilidade de uma ampla compreensão da matemática (bem como de qualquer outro tipo de conhecimento) sem que seja levada em conta uma intrincada rede de relacionamentos que se configura no ambiente onde a matemática é enunciada. Assim, rejeitamos a possibilidade de um conhecimento puro, situado exclusivamente no âmbito das ideias, porque o intelecto já carrega nele próprio as condições conjunturais, e portanto estas questões do tempo e local conformam as próprias ideias. Uma abordagem que não aprofunda as relações presentes no tempo-espaço onde o conhecimento se construiu dá margem a mistérios, coisas inexplicadas e existências autônomas (que surgiram do nada). Por exemplo, o ambiente fértil em ideias que se desenvolveu na Jônia, região que abraçava cidades como Mileto e Samos, de onde vieram Tales e Pitágoras, ainda hoje impressiona historiadores:

A Jônia, e não a península grega foi o verdadeiro berço da filosofia e da matemática dedutiva. Da Jônia também vieram as grandes obras poéticas de Homero (provavelmente de Samos), a llíada e a Odisseia, compostas por volta de 850 a.C. As causas de um dia haver surgido na Jônia uma verdadeira febre intelectual em todas as direções em que o pensamento humano pode se voltar constituem, talvez, o maior mistério da História da Civilização (GARBI 2007, p.19).

Mas o que seria o "maior mistério da História da Civilização" não chegou a surpreender Heródoto. Ao deixar evidentes as demandas daquele povo naquela época, como já foi abordado aqui, a efervescência da vida naquele local explicou o motivo da fertilidade de ideias, desfazendo o mistério.

Sendo as demandas de Platão oriundas da reflexão sobre a sociedade em que vivia, não se espanta que a condução que ele pretendia dar à matemática tenha encontrado acolhimento na mesma sociedade. Assim, acompanhando as demandas conjunturais e a cultura local, a apresentação da matemática foi aos poucos adquirindo traços da organização daquela sociedade. Desde o século VII a.C, as cidades gregas (pólis) contavam com um regime democrático de governo que envolvia os habitantes em processos participativos. Destacam-se em Atenas a Justiça Popular, a Heliéia, criada por Sólon que governou Atenas entre 638 a.C e 558 a.C ou por seu sucessor Clístenes, entre 565 a.C e 492 a.C, e era exercida por um tribunal onde os juízes eram cidadãos escolhidos por sorteio. Eles ouviam a acusação e a defesa e tomavam uma decisão por voto secreto. Além da Justiça Popular, haviam também as Assembleias do Povo, Eclésias criadas por Sólon, em 594 a.C. Todo cidadão ateniense - isso quer dizer homens livres, já que escravos, mulheres e os chamados metecos, estrangeiros que residiam na pólis, não eram considerados cidadãos podia frequentar as reuniões e votar, bastando levantar a mão. Para isso recebia uma quantia em dinheiro (óbolo) a cada sessão. Essas instâncias da democracia grega eram tão presentes no cotidiano do povo que são retratadas em comédias como Assembleia das Mulheres, As vespas ou Pluto, de Aristófanes escrita em 388 a.C. (ARISTÓFANES, 1989).

A tradição das assembleias induzia uma arrumação meticulosa nos argumentos de modo a se tornarem convincentes, e esta prática possivelmente se estendeu aos textos matemáticos. O extremo cuidado com a forma dos enunciados impôs à apresentação da matemática um certo afastamento dos problemas que the serviram de inspiração. 
Aparentando o desprendimento com relação aos problemas do mundo, a matemática foi gradativamente parecendo ser coisa exclusiva do intelecto. Prevaleceu uma apresentação elaborada, lapidada, priorizando o encadeamento (linear), uma matemática dedutiva, que passou a ser confundida com o próprio modo matemático de pensar: "[O método axiomático] não é uma invenção nova; mas seu emprego sistemático como instrumento de descoberta é um dos recursos originais da matemática contemporânea" (BOURBAKI, 2006, p.E.I.8).

Um dos mais importantes e mais antigos livros de matemática que se conhece hoje é Os elementos, de Euclides de Alexandria (330 a.C - ?), escrito por volta de 300 a.C. De acordo com as traduções que dispomos (EUCLIDES,2009) o texto se inicia diretamente em uma sequência de definições, que fixam o significado de alguns conceitos fundamentais, por exemplo, "1. Ponto é aquilo de que nada é parte, 2. Linha é comprimento sem largura, ...". Ao que parece, não há introdução e nem uma palavra explicativa. Presume-se que as definições, bem como o que vem a seguir nos outros 12 livros que compõem Os Elementos, devam ser suficientemente claros e óbvios ao ponto de dispensar qualquer explicação. Segue-se uma sequência de noções comuns, que seriam enunciados verdadeiros em qualquer campo. Depois, os postulados, que seriam enunciados evidentes no campo matemático e por fim as proposições, que deveriam ser derivadas diretamente das definições, noções comuns e postulados. Essa organização parece refletir a concepção de ciência dedutiva formulada pouco antes por Aristóteles, quem já buscava na aritmética e na geometria os termos que se tornariam seus próprios termos técnicos, apropriando-se também de uma ampla diversidade de exemplos matemáticos. Isto tudo serviu, para ele, como exemplo de pensamento necessário ao filósofo (Pereira, 2000, p. 60). Na parte do Organon (nome do conjunto de suas obras a respeito da lógica) intitulada Primeiros Analíticos, ele explica o que pretende designar como ciência dedutiva (demonstrativa):

Devemos, primeiramente, definir o objeto da nossa investigação e o tipo a que pertence. O objeto é a demonstração e o tipo que o realiza é ciência demonstrativa. Devemos a seguir definir uma premissa, um termo, e um silogismo, e a natureza de um perfeito ou imperfeito silogismo; e depois disso, a inclusão ou não inclusão de um termo em outro, assim como em um todo, e o que queremos dizer com predizer um termo de todos, ou de nenhum, ou de outro (ARISTOTLE, p. 81).

Assim, Aristóteles reivindicou para a filosofia o modo esquemático aparentando exatidão e rigor que ele enxergou nas apresentações matemáticas. Seu texto, entretanto, não exibiu diretamente essas características. Embora use letras para representar termos, é ainda repleto de textos explicativos, exemplos, suposições. Completamente diferente do texto que Euclides apresentou n'Os Elementos, que já fez retornar à própria matemática as formas lapidadas pelo filósofo como um modo claro, seco e limpo de pensar.

Para alguns historiadores da matemática (BOYER, 1999, p.71), o que há de novidade nos Elementos com relação à matemática da época não são exatamente os resultados matemáticos, mas a capacidade de organizar e expor a informação. Consideram que Euclides se destacava como professor de matemática, não como matemático, já que não apresentou novos resultados.

Trazendo à vista a produção matemática indiana, destacamos outro autor, C. K. Raju que critica o mito da superioridade da matemática formal e do primado grego. Ele investiga a quem interessa a apresentação dos resultados matemáticos em cada tempo histórico, e portanto, dá visibilidade a uma matemática de compromissos, interesses, uma matemática 
política. Mantendo a arrogância de quem julga ter feito primeiro, Raju transfere para a Índia a primazia na produção matemática. De acordo com Raju, as provas em Os Elementos são essencialmente empíricas (não dedutivas), mas havia uma certa conveniência por parte dos filósofos matemáticos do século XX em convencer que Euclides intencionava a escrita de provas dedutivas, mas falhou em seus esforços (RAJU, 2013). Este ponto é importante porque, como já foi dito aqui, mais tarde, em meados do século $X X$, o estilo de apresentação da matemática passou a ser identificado também como o modo de pensamento evidenciando um contraste entre a "razão lógica" dos matemáticos e a maneira caótica de pensar das pessoas em geral. Mas Morris Kline deixa claro que "a geometria euclidiana não surgiu desta maneira dedutiva. Levou trezentos anos, período que se estendeu de Tales a Euclides, de pesquisa, tateações e argumentos vagos e até incorretos, até que os Elementos pudessem organizar-se. Por conseguinte, os Elementos constituem o produto acabado e relativamente sofisticado de pensamentos muito mais crus e intuitivos" (KLINE, 1976, p.53).

Nos interessa destacar nos Elementos quarto questões que persistiram na Antiguidade Clássica, na Idade Média, ganharam força no século XVII com as concepções Cartesianas e ainda mais nos tempos modernos, embora apresentando focos de instabilidade.

A primeira questão é a apresentação "seca" e linear das teorias matemáticas. Hoje diríamos: exata e objetiva. É um tipo de apresentação compactada, esquemática, que dá a impressão de que não acrescenta nada ao objeto que pretende comunicar. O livro Elementos é escrito em linguagem natural (a linguagem simbólica matemática como conhecemos hoje só seria sistematizada na era moderna) mas percebe-se o esforço pela exatidão e clareza. Hoje este estilo de descrição matemática é conhecido como método axiomático: parte de um pequeno conjunto de afirmações consideradas evidentes e uma maneira considerada precisa de derivar novas verdades a partir das verdades assumidas ou já derivadas. O método axiomático parece atribuir à matemática o poder de alcançar, propagar e desvendar a verdade.

A segunda questão é a abordagem reducionista e totalizadora claramente expressa na noção comum de número 8: "O todo é maior do a parte". Assim, pela junção das partes, configura-se o todo. É essa a estratégia das demonstrações: os mais simples são combinados para formar os mais complexos. Mas não somente isso. O enfoque reducionista também se verifica no esforço de abraçar toda a matemática que se conhecia na época a partir de um conjunto pequeno de regras. Isto demanda a compreensão da matemática como um campo terminado (fechado). Esse ponto de vista torna insuficiente (insatisfatória) qualquer abordagem que não seja tão abrangente quanto a totalidade. A abordagem reducionista atribui à matemática a garantia o domínio total. Além disso, ao apresentar a matemática como uma totalidade (sem fluxo), situa o matemático no papel de descobridor.

A terceira questão é a fidelidade ao real. Na época a matemática tinha o papel de permitir a compreensão do mundo real (as percepções mais imediatas), por isso, deveria ser possível conceber a geometria a partir de fatos simples observáveis e intuitivos. Assim, as "noções comuns", as definições e os postulados, pontos de partida para a abordagem euclidiana, não são demonstrados nem justificados por serem aderentes à intuição. Entretanto, nos salta à vista a complexidade do quinto postulado em relação aos demais. A presença de um enunciado complexo dentre os postulados levanta a suspeita de que o insucesso no desenvolvimento da demonstração também justificou a designação deste enunciado como postulado, sobrepondo-se ao seu "caráter intuitivo". Esse assunto relaciona-se com a compreensão Euclideana do espaço. Sabemos que as concepções 
aristotélica e platônica admitiam que a terra fosse esférica. Em Sobre os Céus, parte 14, escrito em 350 a.C, Aristóteles afirma: "Sobre a posição da Terra e sobre a forma de repousar-se ou movimentar-se, nossa discussão pode terminar aqui. Sua forma é necessariamente esférica" (ARISTOTLE, p.916). Em Fédon, Platão escreve: "a primeira coisa da qual estou convencido é que se a Terra é uma esfera no meio do céu, não tem necessidade de ar ou de qualquer outra força para evitar que caia" (PLATO, p.147).

Ainda assim, a matemática de Euclides se manteve aderente à intuição mais imediata, o espaço plano observável, onde a menor distância entre dois pontos é a linha reta. Está aqui o motivo de chamarmos "Geometria Plana" à geometria concebida no mundo redondo, e que trata também de volumes, mas é expressa no plano, e o espaço é determinado em três dimensões: altura, largura e profundidade. Isto atendeu às expectativas durante muitos séculos seguintes, alcançando tempos em que interessou à igreja forçar a concepção da terra plana. A fidelidade ao mundo real garantiu à matemática um status de absoluta.

Mas as grandes navegações, no século XV, deixaram aparente a concepção da Terra redonda: tornou-se perceptível que, um navio ao se distanciar da costa não despencava no vazio, mas sumia pouco a pouco. Passou a ser necessário considerar os cálculos de grandes distâncias, e então, a menor distância entre dois pontos deixou de ser uma linha reta. Daí então toda a concepção de espaço se modificou. A geometria euclidiana já não suportava modelos inspirados no novo mundo. A partir do século XVII as insatisfações com relação ao quinto postulado se tornaram insustentáveis e terminaram por motivar outras geometrias (não euclidianas) que não são planas, mas elípticas ou hiperbólicas (KUBRUSLY, 2016). Novamente aqui, como nas cavernas, como na matemática grega, a percepção do mundo e da vida expressa em conceitos matemáticos.

A quarta questão é a concepção do espaço como algo fixado, imutável, simétrico, delimitado. Como diz, na definição 1 do livro XI: "O sólido é o que tem comprimento, largura e profundidade". A geometria euclidiana necessita que o espaço seja fixado e estável para poder ser mapeado (controlado). Os cálculos são precisos, explicados algoritmicamente. A matemática controla o espaço, mapeia, conhece e calcula coordenadas.

Tempos recentes, na década de 1970, Foucault, no capítulo O Olho do Poder (FOUCAULT,2013), relacionou a compreensão do espaço com as relações de poder no século XVIII. Argumentou que Jeremy Benthan, ao conceber o panóptico reverteu o conceito de vigilância: não mais a escuridão da masmorra (à qual o olho, com o tempo se habitua), mas o olhar atento e totalizante na claridade, o controle (vigilância) centralizado que tudo alcança. Curioso que o panóptico tenha sido proposto por Benthan, que dedicava uma atenção especial às coisas imediatamente vividas, o bem estar imediato, expresso no princípio da utilidade: "aquele princípio que aprova ou desaprova cada ação de acordo com a tendência que pareça ter de aumentar ou diminuir a felicidade da parte cujo interesse está em questão" (BENTHAN, 1781).

Para Foucault, o estudo do espaço revela os mecanismos do poder. A proposta utilitarista foi concebida sobre a pretensão do estabelecimento de uma separação precisa entre o bem e o mal, que seria capaz de determinar o aumento ou diminuição da felicidade, e o consequente julgamento das ações entre aprovação ou desaprovação. Se por um lado, este estabelecimento de fronteiras se distancia de uma proposta que acompanha demandas da vida, por outro lado, a matemática da vida, assim como o utilitarismo de Benthan, em seus esforços de solucionar os problemas imediatos, deixam transparecer a concepção de mundo que se tinha em cada época. Os matemáticos também se interessaram pelo espaço, 
o mapeamento e controle totalizante por coordenadas. Também na matemática, dominar o espaço significa estabelecer mecanismos de autoridade e poder.

\section{Fora dos trilhos: Matemáticas em correntes e turbilhões}

O filósofo Michel Serres (1930-2019) percebeu a afinidade entre o mundo físico da filosofia de Epicuro (341 a.C a 270 a.C) e a matemática de Arquimedes (287 a.C a 212 a.C). Ele argumentou que os gregos antigos não tinham uma física-matemática unitária como passamos a ter após o Renascimento, e na ausência de uma linguagem comum, produziram dois blocos linguísticos separados: sistemas formais rigorosos e discursos da natureza. Mas há um isomorfismo entre estes blocos que revela a presença da filosofia de Epicuro na produção físico-matemática de Arquimedes (SERRES, 1997, p.25). Nos interessa aqui ressaltar em que sentido essa produção diverge do pensamento científico-tecnológico que se segue até os nossos dias. Nos interessa também verificar que as explicações se aproximam da vida, e do medo da morte, afastando-se da racionalidade platônica e de uma arrumação formal de argumentos. Nos interessa perceber que Arquimedes não somente constrói uma matemática que se fundamenta na prática, mas que o faz com consciência e reflete sobre a separação entre a prática e o formal. Nos interessa ainda ressaltar que, seja no enunciado de um teorema (como em Arquimedes), ou na descrição de uma teoria física (como em Lucrécio) a forma como a mensagem é expressa determina o seu prestígio enquanto ciência, como veremos mais adiante, aderindo ou afastando-se a/de uma ciência nômade ou a uma Ciência de Estado (DELEUZE \& GUATTARI, 2012, p. 25).

Epicuro justificava o conhecimento nas sensações e afetos, considerando que a razão era propensa a enganos. Marcou assim um contraponto à racionalidade platônica sobre a qual se assenta a filosofia ocidental. Sua compreensão do mundo físico e do surgimento das coisas baseava-se numa concepção atomista adaptada de Demócrito (460 a.C a 370 a.C), que tudo explicava na arrumação de átomos em meio ao vazio, onde o termo "átomos" designava as partículas indivisíveis da matéria. Muito se perdeu do trabalho de Epicuro, mas Tito Lucrécio (99 a.C a 55a.C) tomou para si a tarefa de registrar no poema "Sobre a natureza das coisas" (De rerum natura) uma recomposição de parte de obra de Epicuro. Por que em versos? Em versos ele justifica a arrumação e beleza do argumento comparando-os ao cuidado em adoçar um remédio amargo. E no entanto, parece ter sido justamente a escolha pelos versos que lançou sua obra às sombras nas ciências, sendo tomada como uma produção literária e não um tratado científico (SERRES, 1997, p.12,13). Segundo a poesia de Lucrécio, Epicuro explica a infelicidade humana no medo da morte e dos deuses: "temem, após a morte, o castigo eterno." (LUCRÉCIO, I.110), e oferece uma alternativa para libertar a humanidade de seus medos e opressões: o conhecimento e a verdade. Daí então passa à explicação da vida, a partir da compreensão das coisas do mundo, da composição do universo. Tudo é consequência do eterno movimento dos átomos no vazio. Assim, a filosofia de Epicuro é uma ciência dos fluidos. Lucrécio fala de declinação (clinâmen), um pequeno desvio que átomos sofrem quando caem em queda livre (escoamento laminar). Não há uma explicação aparente. O desvio é o "pouco necessário para que seja possível dizer, com isso, que seu movimento mudou", frisa Serres, ressaltando a filiação do atomismo em relação ao cálculo infinitesimal e ao conceito de diferencial (1997, p.13). No livro II, Lucrécio conta que esse pequeno desvio causa uma rearrumação dos átomos, dando origem a tudo que há no mundo. Vê-se portanto que, em De rerum natura, as 
explicações sobre o surgimento das coisas se fundamentam no movimento e na desordem, não na estabilidade, não no equilíbrio. Uma ciência dos fluidos, com explicações inexatas, agrega o caos, focaliza o desvio e se explica no turbilhão, é uma ciência que se aproxima do sensível. Abre o caminho para a matemática anexata de Arquimedes.

Por que Arquimedes levou à frente a hidrostática, mecânica dos fluidos? Serres (1997, p. 17) conjectura que "talvez o mundo mediterrâneo carecesse mais de água que de instrumentos, talvez se inquietasse mais com chuvas, tempestades, rios. Construía reservatórios e aquedutos. A hidráulica importava-Ihe". Daí a principal distinção do que veio a gerar a ciência moderna: a fisica-matemática de Epicuro-Arquimedes-Lucrécio era uma ciência do movimento, não da estática.

Por que o quadro geral da mecânica destacava, e destaca até hoje, a mecânica dos sólidos (estática)? Serres, traz uma resposta, buscando verificar porque o clinâmen, soa como um absurdo (SERRES, 1997, p.12). Ele aponta que desde Galileu, marco inicial da física moderna, a queda dos átomos foi estudada no contexto da mecânica dos sólidos, sendo a mecânica dos fluidos "apenas um caso particular, que os grandes tratados, o de Lagrange por exemplo, só consideravam no final, e marginalmente" (SERRES, 1997, p.14). O traçado histórico linear (do qual Epicuro escapa) em que a ciência moderna assentou suas justificativas racionais mostra que Parmênides de Eléia (530 a.C a 460 a.C) já havia apostado na estabilidade, imobilidade e imutabilidade das coisas que há no mundo. Ele diz que "se alguma coisa existe, não pode nascer ou perecer, transformar-se ou mover-se, nem estar sujeita a qualquer imperfeição." (KIRK, RAVEN e SHOFIELD, 2010, p.251) Os argumentos de Parmênides e as suas paradoxais conclusões tiveram uma enorme influência na filosofia grega posterior; segundo Kirk, Raven e Shofield, um alcance comparado ao cogito de Descartes. A Escola Eleática, à qual pertenceu ele e seu discípulo Zenão de Eléia (495 a.C 425 a.C) valorizou a razão sobre o sensível (KIRK, RAVEN e SHOFIELD, 2010, p.168), de onde derivou-se A=A, a Lei da Identidade. Uma coisa é igual a ela mesma, não há transformação, nem movimento. É a lei do equilíbrio, da coisa estática. Zenão seguiu as conclusões paradoxais de Parmênides e sustentou a unicidade e imobilidade em paradoxos. Da mesma forma, trabalhando com uma contraposição entre o sensivel e as formas discursivas, Zenão formulou o paradoxo de Aquiles, mostrando que o movimento não é possível: "o paradoxo de Aquiles destinava-se, talvez, a provar que, se há muitas coisas, cada uma delas deve ser simultaneamente mais rápida e mais lenta que as outras" (KIRK, RAVEN e SHOFIELD, 2010, p.277). Daí se estabeleceria a ciência moderna com vistas ao equilíbrio das coisas. Arquimedes trabalhou em outras bases. Diz Serres que o que ele indica no início de seu livro é que "a igualdade ou o equilíbrio são apenas casos particulares de proporções ou de ângulos" (SERRES, 1997, p.37). Assim, fica claro que para compreender o equilíbrio é necessário estudar o desequilíbrio. É um contra-sentido, uma dobra, uma estratégia no conhecimento. Uma percepção que se fará necessária e evidente ao longo da história (Cafezeiro, Kubrusly, Cafezeiro, 2016, p.105-106).

Arquimedes, foi um matemático cuja obra e registros históricos mostram uma clara aderência com a vida, impossibilidade em separar uma matemática da vida e de uma outra abstrata. Deixou isto claro em carta a Erastostenes: "muito do que me foi evidenciado pelo meio da mecânica foi posteriormente comprovado por meio da geometria" (ARQUIMEDES, 1909, p.10). Ele partia de experimentações mecânicas para construir suas hipóteses, e então construía demonstrações geométricas. No entanto, sabemos hoje que ele percebeu a necessidade de expressar sua matemática em termos dedutivos. No ano de 1906 o filólogo dinamarquês Johan Ludvig Heiberg teve acesso a um pergaminho da Grécia antiga, cujo 
conteúdo havia sido apagado e sobrescrito com textos litúrgicos, o que era uma prática frequente na idade média. Heiberg conseguiu decifrar os escritos originais e identificou textos de Arquimedes. Dentre eles, a carta a Erastóstenes, onde Arquimedes reconheceu a necessidade de uma versão dedutiva para seus resultados e delegou a Erastóstenes essa tarefa:

Algum tempo atrás eu Ihe enviei alguns teoremas que eu tinha descoberto, anotando apenas as proposições porque eu queria que você encontrasse as demonstrações que não haviam sido dadas. (...) Já que eu vejo, entretanto, como eu disse anteriormente, que você é um estudioso capaz e um proeminente professor de filosofia, e também que você sabe como avaliar um método matemático de investigação, quando há oportunidade, achei por bem analisar e registrar para você neste mesmo livro um método peculiar por meio do qual será possível obter instruções sobre como certas questões matemáticas podem ser investigadas por meio da mecânica (ARQUIMEDES, 1909, p.9,10).

Ele explica seu modo de pensar a matemática: "Pois é claro que é mais fácil de fazer uma prova no caso de se haver obtido antes uma concepção das questões, do que procurá-la sem uma noção preliminar" (ARQUIMEDES, 1909, p.10). Denuncia uma situação anterior em que a concepção da prova por Eudoxo se sobrepôs à concepção da ideia por Demócrito:

Assim, nas familiares demonstrações que Eudoxo teria sido o primeiro a descobrir, ou seja, que um cone e uma pirâmide são um terço do tamanho do cilindro e prisma que têm respectivamente, a mesma base e altura, nenhum crédito é devido a Demócrito que foi o primeiro a fazer essa afirmação sobre esses corpos sem qualquer demonstração (ARQUIMEDES, 1909, p.10).

Mas, identificando a sua própria situação com a de Demócrito, chama atenção à essencialidade do trabalho de concepção de conceitos na matemática da vida e não abre mão de seu papel como matemático, e nem do método de buscar na mecânica o que a geometria viria a confirmar:

Mas estamos na situação de haver encontrado a presente proposição da mesma forma como a referida; e eu decidi escrever e dar a conhecer o método em parte porque já havíamos conversado sobre isso, e assim ninguém pensaria que estaríamos espalhando conversa fiada, e em parte na convicção de que desta forma, estaríamos obtendo não uma pequena vantagem para a matemática, pois na verdade eu assumo que alguém entre os pesquisadores de hoje ou do futuro vai descobrir pelo método aqui estabelecido ainda outras proposições que ainda não ocorreram a nós (ARQUIMEDES, 1909, p.10,11).

A morte de Arquimedes (212 a.c.) em Siracusa serve de marco histórico ao período de fortalecimento do Império Romano e seu domínio sobre o entorno do mar mediterrâneo.

As novas tecnologias daquele tempo e lugar deixaram aparente um fazer científico impregnado de vida, e não completamente submisso ao saber hegemônico. No entanto, já no início do Império Romano, os 12 apóstolos de Cristo iniciaram a difusão de uma fé a partir da tradição judaica, sustentada em um Deus único, abstrato. Era um deus totalizador, todo poderoso, em contraponto ao politeísmo grego, onde diversos deuses exibiam habilidades e responsabilidades diversas, completando-se e às vezes opondo-se em 
violentas disputas. O deus cristão era dotado de uma essência divina, puramente divino, uma harmonia total decorrente da unicidade. Em contraste, a cultura da Grécia antiga era essencialmente híbrida e acolhedora à diversidade. Para os gregos, masculino e feminino podiam coexistir num único corpo como Hermafrodito, filho de Hermes e Afrodite que não tinha gênero definido porque tinha os dois sexos no mesmo corpo. Acolhiam seres humanos-animais, como os centauros, meio homem, meio touro. Deuses e humanos podiam viver, amar, odiar e procriar no mesmo território e tempo. Os deuses gregos tinham um endereço, o Monte Olimpo, que podia ser visto e apontado com o dedo. O amor entre deuses e humanos também era possível e daí geravam-se semi-deuses, como Hércules, filho de Zeus com a mortal Acmena. Em contrapartida, o deus cristão habitava um espaço inacessível aos humanos. Centramento, totalização e essencialidade de um Deus único já dão indícios de uma forma de pensamento que se estabelecia na sociedade e que viria a se fortalecer por muitos séculos. Essa forma de pensamento que se fez evidente na religião acompanhou a sociedade como um todo, manifestando-se também nas expressões das ciências, nas produções das tecnologias, e consequentemente, nas expressões matemáticas, onde o encontro (dos corpos) não é possível (A e A) e não há uma via alternativa (A ou $\sim$ A). Assim se expressam as três Leis da Lógica Clássica, sobre as quais se assentam o empreendimento ocidental da ciência. A primeira lei, formulada por Parmênides, a Lei da Identidade. As seguintes, Lei da Não Contradição e Lei do Terceiro Excluído formuladas por Aristóteles na Metafísica, Livro IV (REALE, 2002, p.143), e em Da Interpretação (ARISTOTLE,2018). A Escola Peripatética, onde movimento já se fazia presente na construção do conhecimento que era elaborado no caminhar, sustentava uma abordagem empírica, contrapondo-se ao racionalismo de Platão, mas, possivelmente pelas mãos dos comentaristas que vieram depois, os tratados de Aristóteles foram organizados de modo a isolar raciocínio e razão como instrumentos para a ciência. Configurou-se, a partir de então, um modo de pensamento que se estabelece em uma separação precisa entre dois valores opostos e essencialmente puros.

No decorrer da ocupação romana a ausência de uma imposição religiosa possibilitou a coexistência de diversas formas de paganismo. Politeístas, as divindades eram encontradas na natureza. No entanto, em certos momentos, a perseguição do Império Romano aos cristãos se intensificou. Na transição dos séculos III para século IV, quando o Império Romano já entrava em decadência, o Imperador precisou reafirmar sua autoridade através de uma divindade protetora, como era costume na cultura pagã e garantir a "paz dos deuses". Os cristãos não aceitavam a divindade do imperador e passaram a ocupar a ilegalidade. Daí se instalou uma "política da intolerância" que não se isolou no plano religioso, mas como uma escolha política, já que a associação do imperador com a divindade fortaleceria a manutenção do poder instituído (OLIVEIRA, 2010). Intensificou-se a perseguiç̧ão aos cristãos. Ainda assim, o cristianismo se fortaleceu. Nas primeiras décadas do século IV, o imperador Constantino se mostrou tolerante ao cristianismo pela promulgação do Édito de Milão (SANTOS, 2006). Pouco mais tarde, no ano 380, o cristianismo tornou-se a religião oficial do Império Romano pela promulgação do Édito de Tessalônica (PAPA, 2016) e, a partir daí, adentrou o período que chamamos de Idade Média (dos séculos $V$ ao XV) e forçando uma reinvenção do legado da antiguidade nesses novos parâmetros totalizadores, centralizadores e essencialistas, onde demandas e inquietações seriam explicadas pela fé. Aí se estabeleceu uma organização política semelhante e paralela ao império, onde o papa passou a figurar como chefe da igreja. "O poder temporal e o poder religioso passaram a se complementar e em pouco tempo se deu uma subordinação 
do poder temporal pelo religioso" (D'AMBROSIO, 1996, pg40). A centralização religiosa, sendo abstrata, ignorava divisões territoriais sobrepondo-se aos poderes locais e estabelecendo um poder único, universal. A possibilidade de uma felicidade na vida eterna, sendo abstrata, oferecia um escape diante da turbulência política, social e econômica da vida terrena (SANTOS, 2006). Nessa nova configuração, a apresentação abstrata da matemática, com seu distanciamento das coisas da vida e do mundo, se mostrou sintonizada a um pensamento onde as respostas às inquietações humanas eram encontradas na fé cristã, apartada das construções da humanidade. A apresentação procedimental da matemática prosseguiu em seu percurso como ciência nômade, subjugada pela Ciência de Estado, como um "gênero de ciência, ou um tratamento da ciência que parece muito difícil de classificar, e cuja história é até difícil de seguir. Não são 'técnicas', segundo a acepção costumeira. Porém tampouco são 'ciências', no sentido régio ou legal estabelecido pela História" (DELEUZE \& GUATTARI, 2012, p. 25).

\section{Duas matemáticas}

Vimos que a matemática antiga sofreu um processo de lapidação priorizando o encadeamento do argumento. Este processo, ao mesmo tempo que posicionou a matemática como uma forma privilegiada de pensar, foi gradualmente omitindo características do espaço-tempo do problema original. Ainda mais, ao mesmo tempo em que foi lapidando-se no sentido de aparentar o desprendimento das coisas da vida, foi também confundindo-se com a sua própria apresentação. A forma dedutiva passou a significar a própria matemática, a despeito de outras possibilidades. Sendo "matemática" palavra de origem grega, "matemathike", onde "máthema" significa compreensão, explicação, ciência, conhecimento, aprendizagem e "thike" significa arte ou técnica de acordo com o dicionário etimológico ${ }^{3}$, houve quem argumentasse que matemática é essencialmente uma criação grega, uma confusão provocada pelo confronto entre etimologia de um termo posteriormente adotado e um processo de criação cujo início coincide com a presença humana no mundo. No entanto, como verificou Arquimedes, a matemática dedutiva é uma forma de apresentação e portanto pressupõe um processo de criação de conceitos. A apresentação procedimental da matemática não oculta esse processo de criação, deixando à vista a aproximação da matemática com o problema que se propõe a resolver. Em função desta aproximação com a vida, a apresentação procedimental foi sendo gradualmente subjugada como uma prática primitiva, uma matemática não evoluída, desvalorizada. Este panorama complexo atendeu a uma certa configuração de poder que se instituiu ao longo da antiguidade grega que valorizava o intelecto e a razão. O processo de conformação dos saberes é invariavelmente um atendimento a uma determinada conjuntura. Isto aplica-se não somente à matemática, mas a qualquer campo do conhecimento e configura duas ciências, uma legitimada (de Estado) e outra marginal (nômade):

[E]ssa ciência nômade não pode ser "barrada", inibida ou proibida pelas exigências e condições da ciência de Estado. (...) É que as duas ciências diferem pelo modo de formalização, e a ciência de Estado não para de

\footnotetext{
${ }^{3}$ http://www.dicionarioetimologico.com.br/matematica/
} 
impor sua forma de soberania às invenções da ciência nômade; só retém da ciência nômade aquilo de que pode apropriar-se, e do resto faz um conjunto de receitas estritamente limitadas, sem estatuto verdadeiramente científico, ou simplesmente o reprime e o proíbe. É como se o "cientista" da ciência nômade fosse apanhado entre dois fogos, o da máquina de guerra, que o alimenta e o inspira, e o do Estado, que the impõe uma ordem das razões (DELEUZE\&GUATTARI, 2012, p. 27-28).

A Ciência de Estado está sempre acompanhada da ciência nômade. Ainda mais, nenhuma delas se sustenta sozinha. Foi o que percebeu Arquimedes no campo da matemática ao pedir a Erastóstenes a demonstração de seus resultados. Deleuze \& Guattari (2012, p.228), mencionando o espaço liso como lugar da ciência nômade, advertiram: "Jamais acreditar que um espaço liso basta para nos salvar".

Um dos fundadores da Ciência da Computação Donald Knuth, percebeu que "[u]ma das maneiras de ajudar a tornar a ciência da computação respeitável é mostrar que ela está profundamente enraizada na história, não apenas em um fenômeno de curta duração" (KNUTH, 1972, p.671). Com essa justificativa ele se dispôs a estudar a matemática babilônica para perceber semelhanças com a matemática algorítmica da computação: "eles representavam cada fórmula por uma lista passo-a-passo de regras para sua avaliação, ou seja, por um algoritmo para calcular essa fórmula." (KNUTH, 1972, p.671)

Reconhecendo que a legitimidade de um campo de saber depende de uma confirguração de poder, Knuth preocupou-se com a incipiente computação. Tomando a matemática ocidental do século XX como referência, ele falou das equações algébricas do nosso tempo como se elas pré-existissem aos problemas da antiguidade que hoje sabemos que são capazes de resolver. Parece enaltecer a capacidade babilônica de resolver problemas, mas está subjulgando a matemática babilônica como um saber não tão evoluído quanto a matemática do nosso tempo. Apostou na matemática (mesmo que na forma que ele próprio julgou antiquada) como justificativa para alçar a computação ao status de ciência.

\section{Referências}

ARISTÓFANES. Pluto (Riqueza). Universidade de Coimbra,1989.

ARISTOTLE, Prior Analytics, On the Heavens, On Interpretation Disponíveis em: https://www.constitution.org/ari/aristotle-organon+physics.pdf Acesso em: 12 jan. 2017.

ARQUIMEDES, Geometric Solutions Derived From Mechanics, 1909. Disponível em: http://www.gutenberg.org/files/7825/7825-pdf.pdf. Acesso em: 13 mai. 2018.

BENTHAM, J. An Introduction to the Principles, Morals Legislation. Batoche Books, 1754.

Disponível em: https://socialsciences.mcmaster.ca/econ/ugcm/3ll3/bentham/morals.pdf. Acesso em: 04 abr. 2019.

BOURBAKI, N. Éléments de Mathematiques, Théorie des Ensambles. Springer, 2006.

BOYER, C. B. História da Matemática. São Paulo: Editora Edgadr Blücher LTDA, 1999.

BRISSON, J. Sexual ambivalence- androginy and hermaphroditism in Greco-Roman Antiquity. Janet Lloyd (Trad.). Berkeley: University of California Press, 2002. 
CAFEZEIRO, I., KUBRUSLY, R., CAFEZEIRO, E. Os números dos mundos. Revista Brasileira de História da Ciência, Rio de Janeiro, v. 9, n. 1, p. 97-112, 2016.

D’AMBROSIO, U. Educação Matemática: da Teoria à Prática. São Paulo: Papirus. 1996.

DELEUZE, G., GUATARRI, F. Mil Platôs. v5. São Paulo: Editora 34, 2012.

EUCLIDES. Elementos. Trad. Irineu Bicudo, São Paulo: Unesp. 2009.

FOUCAULT, M. Microfísica do Poder, São Paulo: Editora Graal, 2013.

FREIRE, P. Entrevista a Ubiratan D'Ambrosio em 1996. Disponível em: https://www.youtube.com/watch?v=245kJbsO4tE. Acesso em: 5 mai. 2016.

GARBI, G. G., A rainha das Ciências, um passeio histórico pelo maravilhoso mundo da matemática, São Paulo: Editora Livraria da Física, 2007

HERÓDOTO (484 A.C. - 425 A.C.). Histórias (Livros 1 a 9), eBooks Brasil, 2006. Disponível em: http://www.ebooksbrasil.org/eLibris/historiaherodoto.html. Acesso em: 9 de jun. 2016.

KIRK, G. S., RAVEN, J. E. Os Filósofos Pré-Socráticos. Lisboa: Calouste Gulbekinan. 1966.

KIRK, G. S., RAVEN, J. E. SHOFIELD, M. Os Filósofos Pré-Socráticos. Lisboa: Calouste Gulbekinan. 2010.

KLINE, M. O fracasso da matemática moderna, São Paulo: IBRASA, 1976.

KNUTH, D. Ancient Babilonian Algorithm. Communications of the ACM, v.15, n.7, 1972.

KUBRUSLY, R. Geometrias não Euclidianas. Uma breve introdução às Geometrias

Hiperbólicas. Disponível em: http://www.im.ufrj.br/ risk/diversos/gne.html. Acesso em: 01 maio 2016.

LUCRÉCIO. Da natureza das coisas. Lisboa, Relógio d'Água, 2015, p. 64-65.

LUCRÉCIO. De la nature des choses Intratext, Disponível em:

http://www.intratext.com/IXT/FRA1461. Acesso em: 12 out, 2018.

OLIVEIRA, J. C. M. A perseguição de Diocleciano na África e os autos da repressão à Igreja de Cirta: os Acta Munatii Felicis. Dimensões, v. 25, n. 25, p.18-31, 2010.

PAPA, H. A. Relações de poder entre bispos e imperador: uma proposta interpretativa acerca da oficialização do cristianismo a partir de Gregório de Nissa e Teodósio I (século IV). História (São Paulo) v.35, e93, 2016 ISSN 1980-4369

PEREIRA, O. P. Ciência e dialética em Aristóteles. São Paulo: Editora Unesp, 2000

PLATÃO. A República. São Paulo: Editora Nova Cultural Ltda, 1997.

PLATO. Five Dialogues, Euthyphro, Apology, Crito, Meno, Phaedo. Second Edition.

Cambridge: Hackett Publishing Company, Inc. Disponível em:

http://philosophyintroduction.weebly.com/uploads/4/4/6/2/44624607/plato_five_dialogues_second_e dition.pdf. Acesso em: 13 mai. 2018.

PLUTARCO, M. Plutarch's Lives. London, 1839. Project Gutenberg. Disponível em http://onlinebooks.library.upenn.edu/webbin/gutbook/lookup?num=674. Acesso em: 13 mai. 2018.

PROCLUS, L. A Commentary on the First Book of Euclid's Elements. Princeton Universty Press, Oxford, 1992. 
RAJU, C. K. (2013). Education and the church: decolonizing the hard sciences. Disponivel em http://ckraju.net/papers/Education-and-counter-revolution.pdf Acesso em: 6 fev. 2016.

REALE, G. Aristóteles Metafísica. São Paulo: Edições Loyola. 2002

RITTER, J. Chacun sa vérité: les mathématiques en Egypte et en Mésopotamie. In: Éléments d'histoir des sciences. Org. Serres, M., 1989.

SANTOS, R. J. M. O Edito de Milão: contexto, texto e pós texto. Maceió: EDUFAL, 2006.

SERRES, M. O nascimento da física no texto de Lucrécio: Correntes e Turbulências. Editora Unesp Edufscar, São Carlos, 1997.

SIMÕES, V. C. L., Resenha de LUCRÉCIO. Da natureza das coisas. Codex - Revista de Estudos Clássicos, Rio de Janeiro, vol. 5, n. 1, 2017, pp. 219-224

SOUZA, J. F., Origens da Civilização Eolo-Jônica. Comentários sobre Homero e Tales de Mileto, Revista de História da USP, n. 26, 1956. 